CORRESPONDENCE

\author{
Basal cell carcinoma after frequent \\ episodes of cutaneous erythema and \\ peeling induced by welding
}

We report a case of basal cell carcinoma located at the sternal angle in a 45 year old boilermaker, who had experienced frequent episodes of welding induced cutaneous erythema and peeling at this site during his 28 year career.

He presented with a $25 \mathrm{~mm}$ x $20 \mathrm{~mm}$ skin lesion overlying the sternal angle which had been present for 6 months. The lesion was excised and histology confirmed the clinical diagnosis of basal cell carcinoma. Before he was told the diagnosis he gave a history of frequent episodes of cutaneous erythema and peeling at the sternal angle. These episodes occurred after welding on days when the $\mathrm{V}$ neck of his shirt was open, thereby exposing the skin to ultraviolet radiation. He estimated this had occurred between once a week and once a month for most of his career. During the first 4 years of his career he undertook manual metal arc welding (MMAW) of mild steel. During the following 24 years he undertook mostly gas metal arc welding (GMAW) of mild steel. $\mathrm{He}$ occasionally undertook gas tungsten arc welding (GTAW) and submerged arc welding (SAW). He occasionally welded aluminium, stainless steel and cast iron. $\mathrm{He}$ lived in the United Kingdom until 7 years old when he moved to Mount Isa, Queensland, Australia, where he remained. $\mathrm{He}$ denied regular outdoor recreation as an adult although he did swim regularly as a child. $\mathrm{He}$ had a fair complexion, green eyes, and light brown hair. He stated that he did not tan easily, and that he developed sunburn easily-skin phenotype SPT $1 .{ }^{1}$ No solar keratoses were found on the face or hands.

Welding induced cutaneous erythema is a recognised condition caused by excessive ultraviolet radiation..$^{2-4}$ Ultraviolet exposure at the chest of arc welders is certainly very high. The average 8 hour dose at this site during GMAW of mild steel has been found to exceed the maximum permissible exposure limit by a factor of 3000. ${ }^{5}$ Prolonged exposure to solar ultraviolet is a risk factor for the subsequent development of skin cancer. $^{16}$

We think that our case is the first report of skin cancer occurring at the site of previous episodes of welding induced cutaneous erythema. The absence of solar keratoses on the hands and face, which are normally covered during welding, suggests that recreational exposure to solar ultraviolet in this tropical location was limited. His skin phenotype (SPT 1) is a recognised risk factor for sunburn and solar ultraviolet induced skin cancer. ${ }^{1}$ It is possible that his skin phenotype rendered him more susceptible to welding induced cutaneous erythema and skin cancer. The latent period of 28 years from the commencement of welding ultraviolet exposure and the first episode of welding induced cutaneous erythema to the development of skin cancer in this case is biologically plausible.
It is possible that episodes of cutaneous erythema due to welding and cumulative ultraviolet exposure from welding are risk factors for the development of skin cancer in welders. It is also possible that ultraviolet from welding and solar ultraviolet interact synergistically in the development of skin cancer. We suggest that further investigation of these possibilities is warranted. The only study of skin cancer in welders of which we are aware found no increase, however, the number of lesions in the study was small. ${ }^{2}$

A MICHAEL DONOGHUE MURRAY J SINCLAIR

The Medical Centre, Mount Isa Mines Limited, Mount Isa, Queensland 4825, Australia

1 Fitzpatrick TB, Johnson RA, Wolff K, et al. Color atlas and synopsis of clinical dermatology. New York: McGraw-Hill, 1997:214-29.

2 Emmett EA, Buncher CR, Suskind RB, et al. Skin and eye diseases among arc welders and Skin and eye diseases among arc welders and
those exposed to welding operations. $\mathcal{F}$ Occup those exposed to we
Med $1981 ; 23: 85-90$.

3 Shehade SA, Roberts PJ, Diffey BL, et al. Photodermatitis due to spot welding. Br f $\mathrm{fer}$ matol 1987;117:117-9.

4 Bruze M, Hindsen M, Trulsson L. Dermatitis with an unusual explanation in a welder. Acta Derm Venereol 1994;74:380-2.

5 Tenkate TD, Collins MJ. Personal ultraviolet radiation exposure of workers in a welding environment. Am Ind Hyg Assoc $\mathcal{F}$ 1997;58:33-

6 Cohen R, Adams RM. Radiation. In: Adams $\mathrm{RM}$, ed. Occupational skin disease, 2nd ed. Philadelphia: Saunders, 1990:65-72.

\section{Work related respiratory symptoms in radiographers}

In 1996 we reported findings from follow up of a large national cohort of radiographers. ${ }^{1}$ The study aimed to assess the nature and scale of a possible respiratory hazard from $x$ ray processing chemicals. In an initial postal survey of all radiographers who registered in the United Kingdom between 1985 and 1989 , we found a clear excess of work related lower respiratory symptoms compared with a control group of physiotherapists. On the face of it, this could represent a high prevalence of occupational asthma, so to explore the question further we sought serial peak flow measurements from 235 radiographers who reported work related wheeze or chest tightness in the postal survey.

Among 235 subjects who reported work related wheeze or chest tightness, 231 had current addresses in the United Kingdom and first registered as radiographers after 1984. This group were sent a second questionnaire asking in more detail about their current job and recent respiratory symptoms. Altogether 163 subjects replied, including 135 who were currently working as radiographers in the United Kingdom. Among these, 71 reported wheeze or chest tightness in the past 3 months and were invited to carry out serial peak flow measurements.

Fifty one radiographers with current wheeze or chest tightness agreed to undertake peak flow monitoring. They were instructed in the appropriate technique at regional workshops, or in a few cases where this was not possible, by telephone. Peak expiratory flow was measured with a miniWright peak flow meter, the best of three consecutive readings being recorded at 2 hourly intervals during waking hours over a period of 4 weeks. For most subjects the recording period included a break from work of a week or longer. The peak flow records were plotted graphically and analysed by a panel of four doctors with expertise in occupational respiratory disease, who independently classified them according to whether they indicated asthma, and if so whether the asthma was related to work.

Twenty usable peak flow records were returned, of which 10 showed evidence of asthma (eight definite and two possible). However, none of the records showed a consistent fall in mean daily peak flow or increase in variability of peak flow on working days compared with non-working days. In the view of the panel none could be classified as showing definite occupational asthma. Three records were considered to show possible occupational asthma.

We recognise that this follow up survey was limited by the few eligible subjects who completed satisfactory peak flow records. The incomplete response could have caused considerable bias if it led to the exclusion of an important number of radiographers with occupational asthma and this was possible at several stages. Firstly, there may have been cases of occupational asthma among nonresponders to the first or second questionnaire. Secondly, some radiographers with occupational asthma may have been excluded from serial peak flow monitoring because they were no longer working. Finally, despite our efforts to encourage compliance, only a few of those who agreed to monitoring completed satisfactory peak flow records and cases of occupational asthma may have been missed as a consequence.

We think it unlikely, however, that there was major underascertainment. If anything we would expect radiographers with work related respiratory symptoms to have responded more readily to the initial questionnaire than those without. And of the 180 who answered the questionnaire and reported symptoms suggestive of occupational asthma but did not attempt peak flow monitoring, at the most only three had ever left a job because of respiratory symptoms. Moreover, none of the subjects whose peak flow records were unsatisfactory had ever been diagnosed as having occupational asthma.

In summary, although we cannot exclude the possibility that some cases in our original cohort have been missed, our findings indicate that occupational asthma in radiographers is rare. The follow up study adds useful information to the earlier report of an excess of respiratory symptoms in a cohort of radiographers, suggesting that at most only a small part of this excess is likely to be attributable to occupational asthma.

JULIA SMEDLEY PAUL CULLINAN ANTHONY FREW ANTHONY NEWMAN-TAYLOR DAVID COGGON

MRC Environmental Epidemiology Unit, University of Southampton, Southampton General Hospital, Southampton SO9 4XY, UK

Correspondence to: Dr Julia Smedley, MRC Environmental Epidemiology Unit, University of Southampton, Southampton General Hospital, Southampton SO9 4XY, UK.

1 Smedley J, Inskip H, Wield G, et al. Work related respiratory symptoms in radiographers. Occup respiratory symptoms in radiogra
Environ Med 1996;53:450-54. 


\section{Air pollution research in the United Kingdom}

Government funded air pollution research in the United Kingdom began in the 1950s as a response to the London smog of 1952. Professor P J Lawther was appointed as the Director of the Medical Research Council (MRC) Air Pollution Research Unit, and with able colleagues, undertook seminal studies that are regarded as landmarks in the field. The Unit closed in the late 1970s.

In the early 1990s, it became clear that the United Kingdom was lagging behind other countries in research on the effects of air pollutants on health and that air pollution was still damaging health. The scale of the effects was unclear but work from the United States suggested that it was larger than expected. In 1994, a workshop was held at the MRC Institute for Environment and Health (IEH) in Leicester. ${ }^{1}$ This workshop drew together recommendations that had been made by several expert advisory committees, identified gaps in knowledge, and drew up a list of priorities for a new research programme. The focus was on research that would have an impact on Government policy. The meeting had far reaching consequences: in October 1994 a call for research proposals was published jointly by the Department of Health, the (then) Department of the Environment, and the Medical Research Council. Proposals were received, peer reviewed, and 25 projects were funded - the United Kingdom was back in the field.

Each year since 1995, a review of the programme, which has expanded and now includes work on indoor air pollutants, has been held at the IEH. The review held in April this year involved 41 research teams and ran for 3 days. Highlights of the review included:

- Work on the chemical composition of the ambient aerosol using the latest scanning electron microscope techniques coupled with electron probe $x$ ray microanalysis methods

- Volunteer studies that reported effects of exposure to air pollutants on variability of heart rate

- Epidemiological work showing changes in red cell counts associated with daily variations in pollutant concentrations

- Time series studies of the associations between daily variations in concentrations of pollutants and a wide range of health effects including deaths and hospital admissions

- Volunteer studies of the effects of diesel exhaust involving bronchoalveolar lavage after exposure and measurement of airway antioxidants

- Studies of the patterns of exposure of people to air pollutants both indoors and outdoors

- Calculation of the shortening of life due to long term exposure to air pollutants.

This research programme has had a considerable effect on policy in the United Kingdom. The current policy is laid out in the United Kingdom National Air Quality Strategy - a revision of the strategy was published in early $1999 .^{2}$

One of the key functions of the annual air pollution research review is to aid government departments in identifying the need for further research and in offering guidance as to its direction. Much remains to be done. A full report of the discussions will be published by the IEH but a few areas are worth listing here:

- The need to clarify exposure-response relations so that the benefits of reducing levels of pollution may be calculated more accurately

- The need to understand the mechanism of action of ambient particles: our understanding of this is still almost negligible

- The need to understand the effects of long term exposure to current concentrations of air pollutants

- The need to identify groups with notably greater than average sensitivity to air pollutants.

These issues will be considered in a new research initiative that the Departments of Health and of the Environment, Transport, and the Regions intend to launch this year.

All this is encouraging. Emissions of air pollutants in the United Kingdom are falling, but effects on health still occur. Understanding these effects and identifying the most effective and efficient measures for further reductions in concentrations will be the challenge for the early years of the new century.

R L MAYNARD Department of Health

1 Medical Research Council, Institute for Environment and Health. IEH report on air pollution and respiratory disease: UK research priorities. Leicester: IEH, 1994.

2 Department of the Environment, Transport, and the Regions. Review of the United Kingdom national air quality strategy. London: DETR, national
1999.

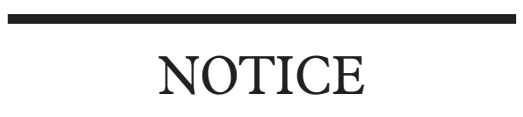

International course: Principles and Methods of Epidemiologic Research

16-19 May 2000. Lunteren, The Netherlands.

The lecturer is KJ Rothman. Among others, the topics will be: case-control research principles, interaction in aetiology, statistics $v$ epidemiologic analyses. Enrollment is open to researchers having basic knowledge of epidemiology and biostatistics and at least some work experience. Closing date for enrollment is 17 January 2000. Course fee: DFL 1950, including a single room with shower/toilet, breakfast, lunches, dinner, coffee/tea during breaks, class notes.

Further information from: Ms Astrid van Alst, Course secretary, Department of Epidemiology, University of Nijmegen, PO Box 9101, NL-6500 HB Nijmegen, The Netherlands. Telephone 003124 3619132; Fax 003124 3613505; email A.VanAlst@, mie.kun.nl

\section{BOOK REVIEWS}

If you wish to order, or require further information regarding the titles reviewed here, please write or telephone the BMJ Bookshop, PO Box 295, London WX1H 9TE. Tel: 0171 383 6244. Fax: 0171383 6662. Payment can be made by cheque in sterling drawn on a UK bank, or by credit card (MasterCard, VISA, or American Express) stating card number, expiry data, and your full name. (The price and availability are occasionally subject to revision by the Publishers.)

Aviation Medicine, 3rd edition. Edited by: Ernsting J, Nicholson A, Rainford D. (Pp 703; £95.00) 1999. Oxford: ButterworthHeinemann. ISBN 0750632526.

This is the eagerly awaited 3rd edition of what has become the international standard textbook for aviation medicine. It is intended primarily for the experienced practitioner engaged in military or civil aviation medicine, but is also directed at those involved in other disciplines of the life sciences in aviation.

Ernsting is the highly respected guru of aviation medicine in the United Kingdom. After a long and distinguished career in the Royal Air Force (mostly at the Institute of Aviation Medicine, Farnborough), he is now visiting professor in human and applied physiology and head of human physiology and aerospace medicine at King's College, London.

Nicholson is a former commandant of the RAF School of Aviation Medicine and is visiting professor of aviation medicine, human physiology and aerospace medicine at King's College, London.

Rainford continues to serve in the Royal Air Force as clinical director, and is a consultant to the United Kingdom Civil Aviation Authority.

It is thus no surprise that this book is comprehensive and authoritative, being particularly strong in human physiology and the physiological effects of the aviation environment. There is no attempt to cover space medicine, which is expanding into a specialty in its own right.

The book is divided into three parts, covering aviation physiology and aircrew systems, clinical aviation medicine and operational aviation medicine. The editors have been largely successful in achieving a unity of style throughout, which is no mean feat given more than 40 contributors. There is an inconsistency in the fact that many chapters end with a further reading list, which in some cases is not as comprehensive as expected, whereas other chapters end with a detailed reference list. Some of the diagrams have been carried through successively from the first edition and are beginning to look a little tired.

This edition is about 30 pages shorter than its predecessor, which in turn was shorter than the two volume format of the first edition. This is a tribute to tight editing, but I searched in vain for detailed information on commercial aircraft medical kits. The chapter dealing with the health of the airline passenger is a reprint of the basic guidelines issued by the Aerospace Medical Association. I would have expected an authoritative text to have a wider and deeper consideration of one 
of the more important issues facing practitioners of civil aviation medicine.

The military pedigree of the distinguished editors is evident throughout. This is not a serious criticism, but the broader issues of the civilian aviation environment (particularly the commercial considerations) deserve wider exposition.

Despite its high price, this volume is essential reading for candidates for the Diploma in Aviation Medicine, and should be on the bookshelf of every practitioner of aviation medicine. However, I cannot yet bring myself to throw away my old copy of Gillies Textbook of aviation physiology!

MICHAEL BAGSHAW

Lung biology in health and disease series. Vol 100. Edited by: JOHN A MCDONALD (Pp 740; $£ 215.00)$ 1997. New York: Marcel Dekker. ISBN: 0-82479772-8.

This is the 100th volume of this series and it is interesting to compare it with one of the earlier ones entitled "Development of the Lung. Vol 6". The intervening years have seen an explosion in our knowledge of the lung and this book must be almost twice as big as its predecessor but even so it has not been able to encompass all the new developments in the field. Nevertheless, the editors have made an interesting choice on what to include, balancing old favourites with newer areas of interest and overall I think that they have done justice to the main advances that have taken place since volume 6 . The more traditional topics have not been neglected but have been brought up to date.

The first chapter, almost de rigeur nowadays in a book on this subject, is by Burri. He presents consistently high standard beautiful histological pictures which with the accompanying diagrams make a very clear exposition of how the lung develops in three dimensional space. This chapter also contains collected basic morphometric data on the lung which is always useful. Another regular is the chapter on pulmonary surfactant, as always meticulously researched and referenced by Ballard assisted by Odom. But perhaps it is not fair to pick out some authors when most of the contributor's names will be familiar to those interested in lung physiology and the leading researchers in their respective areas have been chosen to write each topic.

Newer topics have been introduced, as should be the case in a book of this quality. They include chapters on the transcription factors important in development of certain cellular components, on various components of the lung intercellular matrix including laminin, collagens, and elastic fibres and on the role of neuropeptides in lung development. The volume ends with some interesting chapters, which are quite appropriately included, on lung injury to the developing lung, on in vitro models of lung development, and on the hormonal control of compensatory lung growth.

I found it a wonderful volume to dip into. It will be an excellent reference and teaching resource for some time to come for it is difficult to think of where else such a concentration of high quality chapters on lung development could be obtained. I have two reservations, however. Firstly, a volume of this nature would be expected to be a little out of date by the time it is published but even so it seems that the most recent references included are only those up to 1996 , suggesting a delay somewhere along the publishing line. Secondly the price of $£ 215$ puts it way beyond the reach of any student (and indeed of most teachers and perhaps even of well endowed libraries); one wonders at what market the publishers are aiming. Nevertheless, my copy will remain in a very accessible position on my shelf. I anticipate that it will become well thumbed over the years by my students and by me so the good quality glossy paper on which the book is printed is a real bonus.

\section{V WALTERS}

Approaches to Predicting Toxicity from Occupational Exposure to Dusts, IEH report R11. Edited by: Linda, Shuker, Len, Levy. (Pp 144; £25) 1999. Leicester: Institute for Enviroment and Health. ISBN 1899110208 .

This report of a workshop at the Institute for Enviroment and Health is a fairly comprehensive and timely summary of the current conflicting interpretations of the effects of low solubility particles. The workshop was convened by the Health and Safety Executive. This shows in the subject matter which concentrates on the implications of the more recent discoveries for standard setting and risk assessment.

Occupational health professionals, aware of the historical problems with dusts, want materials classified into broad groups with simple rules to regulate exposure. For a time it seemed that the concept of low toxicity dusts, with the respirable fraction as a magic number to separate the possible long term responses from the shorter term reactionssuch as irritation or allergy-might fill this need. Lung tumours in rats after massive exposures to "inert" dusts and recent obser- vations that very fine particles provoke different responses, caused a reappraisal.

The problem is that the subject is still largely in the descriptive phase with no real knowledge of mechanism to provide a secure basis for classification or regulation. Almost all industrial exposures are to mixtures of dusts with composition varying over time. Add to this the often substantial delay between exposure and effect and patchy exposure records: the chance of establishing secure causative associations by epidemiological investigations in shifting populations is not good.

Academics dip into the subject from time to time often without a real understanding of the problem but with a conviction that their latest cytokine provides the unifying link to the diversity of biology in this area. All too often they find the problems intractable and withdraw.

Industrial researchers have generally confined their efforts to product defence. A few companies recognised the potential value of a sound scientific base for this and the sector has made a significant contribution to the science in recent years, although the real breakthrough continues to be elusive.

All these disciplines were represented at this workshop so the diversity of approach is evident from the text, even though the pragmatists were in the majority. Students and those involved with industrial safety will find the summaries in this volume invaluable as the information is difficult to glean from the diverse literature.

The discussion section is less enlightening, with frank conflict in places. Thus, the carcinogenic responses found in rats at very high dust levels are discounted as reflecting "overload"- a response without direct parallel in other rodent species and humans. Even so, evaluation of new particulates in a rat model is advocated. Workshops of this type usually result in bland conclusions. Those with revolutionary ideas tend to apply them rather than share them in open forum. Research to date has been the usual mixture of the thoughtful and the pragmatic: with a tendency for pragmatism to predominate. Nevertheless the need for more (multidisciplinary) research was identified (is there an Institute for Enviroment and Health forum which has concluded otherwise?). The real need is for an improved dialogue between the interested parties which might just lead to a new and informative approach to the problems. This publication is a useful contribution.

At $£ 25$ this slim volume seems expensive, reflecting the specialist audience.

G H PIGOTT 